\title{
In Vitro Versus in Situ Ruminal Biohydrogenation of Unsaturated Fatty Acids from a Raw or Extruded Mixture of Ground Canola Seed/Canola Meal
}

\author{
F. Enjalbert, ${ }^{*}$ P. Eynard, ${ }^{\star}$ M. C. Nicot ${ }^{\star}$, A. Troegeler-Meynadier, ${ }^{\star}{ }^{C}$ C. Bayourthe, $\dagger$ and R. Moncoulon $\dagger$ \\ *Ecole Nationale Vétérinaire, Département Elevage \& Produits, \\ Laboratoire d'Alimentation, 23 Chemin des Capelles, 31076 \\ Toulouse Cedex, France \\ †Ecole Nationale Suprieure Agronomique, Laboratoire d'Ingénierie \\ Agronomique, Avenue de l'Agrobiopôle, BP 107, Auzeville-Tolosane, 31326 \\ Castanet Tolosan Cedex, France
}

\section{ABSTRACT}

Raw or extruded blends of ground canola seeds and canola meal were used to compare in vitro and in situ lag times and rates of disappearance due to ruminal biohydrogenation of unsaturated fatty acids. The in situ study resulted in higher lag times for biohydrogenation for polyunsaturated fatty acids and lower rates of biohydrogenation of unsaturated fatty acids than the in vitro study, so the in situ biohydrogenation of polyunsaturated fatty acids was not complete at $24 \mathrm{~h}$ of incubation. With both methods, rates of biohydrogenation of polyunsaturated fatty acids were higher than for cis$\triangle 9 \mathrm{C} 18: 1$. Extrusion did not affect the rate of biohydrogenation of cis- $\triangle 9 \mathrm{C} 18: 1$, but resulted in higher rates of biohydrogenation of polyunsaturated fatty acids with higher proportions of trans intermediates of biohydrogenation at $4 \mathrm{~h}$ of incubation in vitro and at $8 \mathrm{~h}$ of incubation in situ. These results suggest that extrusion affects the isomerization of polyunsaturated fatty acids, rather than the hydrogenation steps. In conclusion, in vitro and in situ methods can both show differences of ruminal metabolism of unsaturated fatty acids due to processing, but the methods provide very different estimates of the rates of disappearance due to biohydrogenation.

(Key words: biohydrogenation, canola, in situ, in vitro)

Abbreviation key: $\mathbf{B H}=$ biohydrogenation, $\mathbf{C L A}=$ conjugated linoleic acid, FA = fatty acid, $\mathbf{R B C}=$ raw blend of ground canola seeds and canola meal, EBC = extruded blend of canola seeds and canola meal, UFA = unsaturated FA.

Received February 4, 2002.

Accepted May 25, 2002

Corresponding author: F. Enjalbert; e-mail: f.enjalbert@envt.fr.

\section{INTRODUCTION}

The ruminal digestion of lipids results in major changes of the profile of dietary fatty acids (FA) due to biohydrogenation (BH) of unsaturated FA (UFA). Intermediates of $\mathrm{BH}$, such as conjugated linoleic acid (CLA) and trans- $\triangle 11 \mathrm{C} 18: 1$ as a precursor of CLA in the mammary gland of the cow (Griinari et al., 2000) and in human (Adlof et al., 2000) possess interesting dietary properties for human. Increased milk concentration of both CLA and trans-C18:1 can be obtained by extrusion of oilseeds (Chouinard et al., 1997a; Bayourthe et al., 2000; Chouinard et al., 2001).

Comparisons of the $\mathrm{BH}$ patterns of UFA from unprocessed or processed sources of lipids are usually performed in vivo via comparison between dietary and duodenal flows of FA (Enjalbert et al., 1997; Murphy et al., 1987) or in vitro via the measurement of disappearance of UFA (Harfoot et al., 1973a; Wu and Palmquist, 1991; Beam et al., 2000). In vivo methods are very expensive and time-consuming, and the results obtained in vitro can vary largely as a function of fermentation conditions (Gerson et al., 1983, 1985, 1988; Van Nevel and Demeyer, 1996).

In situ methods have the advantage to incubate substrates in a more physiological milieu than in vitro procedures. They have been widely used for the study of ruminal degradation of protein or fiber but have been infrequently used for the study of ruminal metabolism of lipids (Perrier et al., 1992; Chouinard et al., 1997b).

The objectives of this study were to ascertain the effects of extrusion of canola seeds on lag time and rate of BH of UFA and, using an in vitro study as a reference, to evaluate the accuracy of an in situ procedure for comparison of raw and extruded ground canola.

\section{MATERIALS AND METHODS}

\section{Preparation of Canola}

Because extrusion of whole fat canola seeds is difficult, a blend of raw canola seeds and canola meal (50/ 
Table 1. Ingredient and nutrient composition of diets (DM basis).

\begin{tabular}{lr}
\hline Ingredients & $\%$ \\
Corn silage & 38.4 \\
Ray-grass hay & 54.0 \\
Soybean meal & 6.8 \\
Mineral-vitamin mix ${ }^{1}$ & 0.8 \\
Nutrient analysis, g/kg & 11.3 \\
CP & 2.4 \\
Fat & 26.6 \\
ADF
\end{tabular}

${ }^{1}$ Contained $5 \% \mathrm{P}, 14 \% \mathrm{Ca}, 6 \% \mathrm{Na}, 4 \mathrm{~g}$ of $\mathrm{Zn} / \mathrm{kg}, 3.2 \mathrm{~g}$ of $\mathrm{Mn} / \mathrm{kg}, 3$ $\mathrm{g}$ of $\mathrm{Fe} / \mathrm{kg}, 0.8 \mathrm{~g}$ of $\mathrm{Cu} / \mathrm{kg}, 250,800 \mathrm{IU}$ of vitamin $\mathrm{A} / \mathrm{kg}, 62,700 \mathrm{IU}$ of vitamin D3/kg, and $112 \mathrm{IU}$ of vitamin $\mathrm{E} / \mathrm{kg}$.

50 wt) were used after grinding through an 8-mm screen. Part of this raw blend of canola (RBC) was used to prepare an extruded blend of canola $\left(\mathbf{E B C}, 140^{\circ} \mathrm{C}\right.$ exit temperature; Extruder Clextral, BC 45, Firminy, France). Both blends were ground through a 2-mm screen before incubations. The FA composition of RBC and $\mathrm{EBC}$ is presented in Table 2.

\section{In Vitro Experiment}

The day before each series of incubation, $1.5 \mathrm{~g}$ of ground peas as a source of $\mathrm{N}$ and starch for fermentation and $4 \mathrm{mg}$ of soybean phosphatidylcholine (SigmaAldrich Chimie, Saint Quentin Fallavier Cedex, France) dissolved in $1 \mathrm{ml}$ diethyl ether (Merck, Darmstadt, Germany) to improve lipid dispersion were set into $250-\mathrm{ml}$ flasks. Control cultures and cultures with $800 \mathrm{mg}$ of added RBC or EBC were prepared. Moreover, at $1700 \mathrm{~h}$, nylon bags containing $3.5 \mathrm{~g}$ of hay ground through a 5 -mm screen were introduced into the rumen of a fistulated dry Holstein cow receiving a diet based on corn silage, hay, and soybean meal (Table 1).

The day of incubation, at $0800 \mathrm{~h}$, nylon bags were removed from the cow, and ruminal fluid was collected, strained through a metal sieve $(0.8 \mathrm{~mm}$ mesh $)$ and

Table 2. Dry matter and fatty acid composition of raw and extruded blends of ground canola seeds and canola meal.

\begin{tabular}{|c|c|c|}
\hline Treatment & Raw & Extruded \\
\hline DM, \% & 90.0 & 94.0 \\
\hline Total fatty acids & 19.0 & 20.1 \\
\hline Total C18 & 15.8 & 16.9 \\
\hline C18:0 & 1.97 & 1.90 \\
\hline$c i s-\mathrm{C} 18: 1^{2}$ & 61.63 & 61.17 \\
\hline$c i s-\mathrm{C} 18: 2^{2}$ & 25.17 & 25.24 \\
\hline$c i s-\mathrm{C} 18: 3^{2}$ & 11.17 & 11.69 \\
\hline
\end{tabular}

\footnotetext{
${ }^{1}$ Fatty acids with 18 carbons.

${ }^{2}$ cis-C18:1 refers to cis- $\Delta 9 \mathrm{C} 18: 1$, cis-C18:2 refers to cis- $\Delta 9$, cis$\Delta 12 \mathrm{C} 18: 2$, cis-C18:3 refers to $c i s-\Delta 9$, cis- $\Delta 12$, cis- $\Delta 15 \mathrm{C} 18: 3$.
}

brought to the laboratory (30 min). The incubated hay from a nylon bag was added into each flask as a source of fiber and solid-adherent bacteria, because BH takes place on lipids adsorbed onto food particles (Harfoot et al., 1973b). In each flask were added $80 \mathrm{ml}$ of ruminal fluid, and $80 \mathrm{ml}$ of a buffer solution containing $(\mathrm{g} / \mathrm{L})$ : $\mathrm{NaHCO}_{3}, 9.24 ; \mathrm{Na}_{2} \mathrm{HPO}_{4} .2 \mathrm{H}_{2} \mathrm{O}, 19.5 ; \mathrm{NaCl}, 0.705 ; \mathrm{KCl}$, $0.675 ; \mathrm{CaCl}_{2} .2 \mathrm{H}_{2} \mathrm{O}, 0.108$, and $\mathrm{MgSO}_{4} .7 \mathrm{H}_{2} \mathrm{O}, 0.180$, prewarmed at $39^{\circ} \mathrm{C}$, and saturated with $\mathrm{CO}_{2}(\mathrm{pH} 6.9)$.

The flasks were gassed with $\mathrm{CO}_{2}$ before closing, placed in a water bath rotary shaker (Aquatron; Infors $\mathrm{AG}, 4103$ Bottmingen, Germany) at $39^{\circ} \mathrm{C}$, and stirred at $130 \mathrm{rpm}$. Incubation times for control and canola cultures were 2, 4, 8, 16, and $24 \mathrm{~h}$. Each series of incubation comprised 15 flasks (i.e., for each incubation time, a control culture, a culture with $\mathrm{RBC}$, and a culture with EBC. A supplemental control flask without incubation was kept with each series. Five replicates were incubated for each form of canola and each incubation time. Incubations were stopped by placing the flasks into iced water. Contents of the flasks were then frozen, freeze-dried (Virtis Freezemobile 25; Virtis, Gardiner, $\mathrm{NY}$ ), weighed, and kept at $-18^{\circ} \mathrm{C}$ until analysis.

\section{In Situ Experiment}

Two ruminally-fistulated Holstein dry cows were used. Heat-sealed nylon bags $(11 \times 6 \mathrm{~cm}$; mean pore size $45 \mu \mathrm{m}$; Blutex, Tissage Tissus Techniques, Combles, France) were filled with $3 \mathrm{~g}$ of RBC or EBC. Bags with incubation times of $2,4,8$, and $24 \mathrm{~h}$ were introduced into the rumen before the morning meal, and bags with incubation time of $16 \mathrm{~h}$ were introduced before the evening meal. For each incubation time, two replicates were made on each cow. After removal from the rumen, bags were rinsed for approximately 2 min in cold water until no color appeared in the rinse water, frozen at $-18^{\circ} \mathrm{C}$ during $24 \mathrm{~h}$, machine-washed $(2 \times 5 \mathrm{~min})$ in cold water, freeze-dried, weighed, and stored at $-18^{\circ} \mathrm{C}$ until analysis. Zero-hour bags were incubated for $1 \mathrm{~h}$ in water $\left(38^{\circ} \mathrm{C}\right)$, and rinsed, washed, dried, and stored with a similar procedure.

Additionally, the FA composition of material retained in bags incubated in sterilized rumen fluid was investigated to ascertain whether all individual FA had equal losses from the bags. Bags containing RBC or EBC were incubated in $250-\mathrm{ml}$ flasks containing $200 \mathrm{ml}$ of sterilized ruminal fluid and $0.5 \mathrm{~g}$ of pancreatin (Sigma Aldrich) in order to hydrolyze triacylglycerols and proteins, because these hydrolyzes, due to microorganisms in the rumen, may affect losses of FA. Two replicates of RBC and $\mathrm{EBC}$ were incubated in a water bath rotary shaker during $2,4,8$, and $16 \mathrm{~h}$. After incubation, the bags were 
washed, dried, and stored with the same procedure as bags incubated in situ.

\section{Analysis of Fatty Acids}

Samples were ground using a ball mill (Dangoumau, distributed by Prolabo, Nogent-sur-Marne, France). The FA of feed samples and residues of incubation were extracted and methylated with a one-step procedure (Sukhija \& Palmquist, 1988). The FA methyl esters were then quantified by GLC (Dani GC 1000, Monza, Italy). The column was a fused silica capillary (CPSil88, $100 \mathrm{~m} \times .25 \mathrm{~mm}$ ID, $0.20 \mu \mathrm{m}$ film thickness; ChrompackVarian, Middleburg, the Netherlands). The carrier gas was helium at a constant flow of $1 \mathrm{ml} / \mathrm{min}$. The flame ionization detector was set at $260^{\circ} \mathrm{C}$, and the split ratio in the injector $\left(255^{\circ} \mathrm{C}\right)$ was 50:1. Oven temperature was initially $50^{\circ} \mathrm{C}$ and increased by $4^{\circ} \mathrm{C} / \mathrm{min}$ to $200^{\circ} \mathrm{C}$, maintained at $200^{\circ} \mathrm{C}$ for $10 \mathrm{~min}$, increased by $4^{\circ} \mathrm{C} / \mathrm{min}$ to $225^{\circ} \mathrm{C}$, maintained at $225^{\circ} \mathrm{C}$ for $5 \mathrm{~min}$, increased by $5^{\circ} \mathrm{C} / \mathrm{min}$ to $230^{\circ} \mathrm{C}$, and maintained at $230^{\circ} \mathrm{C}$ for $2 \mathrm{~min}$.

With this method, the peaks of trans- $\Delta 10 \mathrm{C} 18: 1$ and trans- $\Delta 11 \mathrm{C} 18: 1$ are difficult to separate one from another, but are separated from peaks of other C18:1 cis or trans isomers, so that FA designated as trans-C18:1 in this paper refers to both trans- $\Delta 10 \mathrm{C} 18: 1$ and trans$\Delta 11 \mathrm{C} 18: 1$. For simplification, FA designated as cis$\mathrm{C} 18: 1$, cis-C18:2, and cis-C18:3 will refer to cis$\Delta 9 \mathrm{C} 18: 1$, cis- $\Delta 9$, cis- $\Delta 12 \mathrm{C} 18: 2$, and cis- $\Delta 9$, cis- $\Delta 12$, cis- $\Delta 15 \mathrm{C} 18: 3$, respectively, and CLA will refer to the cis- $\Delta 9$, trans- $\Delta 11 \mathrm{C} 18: 2$ isomer.

\section{Calculations and Statistics}

For the in vitro experiment, FA from substrate and inoculum were excluded by subtracting from the FA in cultures with added canola the FA in the control cultures incubated on the same day and during the same time. Such a calculation, already used by others (Beam et al., 2000), assumes that addition of a source of FA does not affect the metabolism of FA from the inoculum or the other substrates.

In both in vitro and in situ experiments, estimation of $\mathrm{BH}$ was based on the disappearance of UFA, as in previous studies (Wu and Palmquist, 1991; Reddy et al., 1994; Beam et al., 2000). Estimation of parameters of $\mathrm{BH}$ kinetics was based on the exponential model of Orskov and McDonald (1979) and assumed that no immediate disappearance of UFA due to $\mathrm{BH}$ could occur, and that all the initial amount of UFA could be hydrogenated.

For the in vitro experiment, no loss of total $\mathrm{C} 18$ from the flasks could occur so that at each time of incubation:

$$
\mathrm{AC} 18=\mathrm{A} 0 \mathrm{C} 18
$$

where, $\mathrm{AC} 18=\mathrm{mg}$ of total $\mathrm{C} 18$ at $\mathrm{t} \mathrm{h}$ of incubation, and $\mathrm{A} 0 \mathrm{C} 18=\mathrm{mg}$ of total $\mathrm{C} 18$ added into the flask. Due to $\mathrm{BH}$, the amount of each UFA remaining in the flasks depended on incubation time as follows:

$$
\mathrm{A}=\mathrm{A} 0 \cdot \mathrm{e}^{-\mathrm{c} \cdot(\mathrm{t}-\mathrm{l})}
$$

where, $\mathrm{A}=\mathrm{mg}$ of the UFA at $\mathrm{t} \mathrm{h}$ of incubation, $\mathrm{A} 0=$ $\mathrm{mg}$ of the UFA added into the flask, $\mathrm{c}=$ rate of $\mathrm{BH}$, and $\mathrm{l}=$ lag time before the $\mathrm{BH}$ begins. Dividing the expression [2] by the expression [1], we obtained:

$$
\mathrm{P}=\mathrm{P} 0 \cdot \mathrm{e}^{-\mathrm{c} \cdot(\mathrm{t}-\mathrm{l})}
$$

where, $\mathrm{P}=\mathrm{A} / \mathrm{AC} 18=$ proportion of the UFA at $\mathrm{t} \mathrm{h}$ of incubation and $\mathrm{P} 0=\mathrm{A} 0 / \mathrm{A} 0 \mathrm{C} 18=$ initial proportion of the UFA in the experimental substrate.

For the in situ experiment, zero-hour bags were used for values at $t=0$, and we took into account both disappearance due to physical loss of FA from the bag and disappearance due to BH. Due to loss of FA, the amount of total C18 remaining in the bag after $t h$ of incubation was:

$$
\mathrm{AC} 18=\mathrm{A} 0 \mathrm{C} 18 \cdot \mathrm{R}
$$

where, $\mathrm{AC} 18=\mathrm{mg}$ of total $\mathrm{C} 18$ at $\mathrm{t} \mathrm{h}$ of incubation, $\mathrm{A} 0 \mathrm{C} 18=\mathrm{mg}$ of total $\mathrm{C} 18$ at $\mathrm{t}=0$, and $\mathrm{R}=$ proportion of total $\mathrm{C} 18$ remaining in the bag a $\mathrm{t} \mathrm{h}$ of incubation.

Because in this experiment incubation of bags in sterilized rumen fluid showed that all C18 FA had similar losses from the bags and because disappearance of UFA was due both to loss of FA and $\mathrm{BH}$, the amount of each UFA remaining in the bag after $\mathrm{t} h$ of incubation was:

$$
\mathrm{A}=\mathrm{A} 0 \cdot \mathrm{R} \cdot \mathrm{e}^{-\mathrm{c} \cdot(\mathrm{t}-\mathrm{l})}
$$

where, $\mathrm{A}=\mathrm{mg}$ of the UFA at $\mathrm{t} \mathrm{h}$ of incubation, $\mathrm{A} 0=$ mg of the UFA at $\mathrm{t}=0, \mathrm{c}=$ rate of $\mathrm{BH}$, and $\mathrm{l}=$ lag time before the $\mathrm{BH}$ begins. Dividing the expression [4] by the expression [3], we obtained:

$$
\mathrm{P}=\mathrm{P} 0 \cdot \mathrm{e}^{(-\mathrm{c} \cdot(\mathrm{t}-\mathrm{l}))}
$$

which was the same model as that used for the in vitro experiment.

Data were computed with the nonlinear regression procedure of SYSTAT (Version 9; SPSS Inc., 1998, Chicago, IL). Lag time for $\mathrm{BH}$ was considered different from zero when its confidence interval did not contain zero. 
Table 3. In vitro experiment: lag time and rate of biohydrogenation of unsaturated fatty acids from canola (mean $\pm \mathrm{SEM})$.

\begin{tabular}{|c|c|c|}
\hline Treatment & Raw & Extruded \\
\hline \multicolumn{3}{|l|}{ cis-C18: $1^{1}$} \\
\hline Lag time, $\mathrm{h}$ & $-0.43 \pm 0.28$ & $-0.11 \pm 0.44$ \\
\hline Rate of biohydrogenation, $\% / \mathrm{h}$ & $10.4 \pm 0.6$ & $11.2 \pm 1.1$ \\
\hline 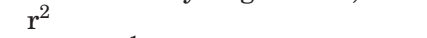 & 0.99 & 0.97 \\
\hline \multicolumn{3}{|l|}{ cis-C18: $2^{1}$} \\
\hline Lag time, $\mathrm{h}$ & $-0.01^{\mathrm{c}} \pm 0.17$ & $1.14^{\mathrm{a} . \mathrm{b}} \pm 0.18$ \\
\hline Rate of biohydrogenation, $\% / \mathrm{h}$ & $19.1^{\mathrm{c}} \pm 1.0$ & $37.5^{\mathrm{b}} \pm 4.2$ \\
\hline $\mathrm{r}^{2}$ & 0.99 & 0.97 \\
\hline \multicolumn{3}{|l|}{ cis $\mathrm{C} 18: 3^{1}$} \\
\hline Lag time, $\mathrm{h}$ & $-0.35^{\mathrm{c}} \pm 0.25$ & $1.04^{\mathrm{a}, \mathrm{b}} \pm 0.17$ \\
\hline Rate of biohydrogenation, $\% / \mathrm{h}$ & $20.4^{\mathrm{c}} \pm 1.6$ & $45.8^{\mathrm{b}} \pm 5.3$ \\
\hline $\mathrm{r}^{2}$ & 0.98 & 0.97 \\
\hline
\end{tabular}

${ }^{a}$ Value significantly different from zero $(P<0.05)$.

${ }^{\mathrm{b}, \mathrm{c}}$ Means in the same row with unlike superscripts differ $(P<0.01)$.

${ }^{1}$ cis-C18:1 refers to $c i s-\Delta 9 \mathrm{C} 18: 1$, cis-C18:2 refers to $c i s-\Delta 9$, cis- $\Delta 12 \mathrm{C} 18: 2$, cis-C18:3 refers to $c i s-\Delta 9$, cis$\Delta 12$, cis- $\Delta 15 \mathrm{C} 18: 3$.

For the in vitro and the in situ experiments separately, lag times and rates of $\mathrm{BH}, \mathrm{RBC}$, and $\mathrm{EBC}$ were compared using the model:

$$
\mathrm{P}=(\mathrm{P} 0+\Delta \mathrm{P} 0 \mathrm{TRT}) \cdot \mathrm{e}^{(-(\mathrm{c}+\Delta \mathrm{ce} \cdot \mathrm{TRT})(\mathrm{t}-(1+\Delta \mathrm{le} \cdot \mathrm{TRT})))}
$$

where, $\Delta \mathrm{P} 0=$ difference of proportion of each FA between RBC and EBC, TRT is coded 0 for RBC and 1 for $\mathrm{EBC}$, so that $\Delta$ ce and $\Delta$ le are the effects of extrusion on rate and lag time of $\mathrm{BH}$, respectively. The effects of extrusion were declared significant when the confidence interval of $\Delta$ ce and $\Delta$ le did not contain zero.

The effects of method of investigation and interaction of extrusion by method of investigation were tested using the model:

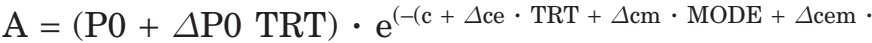
$\mathrm{TRT} \cdot \mathrm{MODE})(\mathrm{t}-(\mathrm{l}+\Delta \mathrm{le} \cdot \mathrm{TRT}+\Delta \mathrm{lm} \cdot \mathrm{MODE}+\Delta \mathrm{lem} \cdot \mathrm{TRT} \cdot \mathrm{MODE})))$ where, MODE is coded 0 for the in vitro experiment and 1 for the in situ experiment, so that $\Delta \mathrm{cm}$ and $\Delta \mathrm{lm}$ are the effects of method on rate and lag time of $\mathrm{BH}$, respectively, and $\Delta$ cem and $\Delta$ lem are the effects of interaction of extrusion by method on rate and lag time of $\mathrm{BH}$, respectively.

At each time of incubation, the proportions of each FA were compared between RBC and EBC for the in vitro and the in situ experiments separately, using the general linear model of SYSTAT.

\section{RESULTS}

In the in vitro experiment, most lag times for $\mathrm{BH}$ of the UFA were not significantly different from zero, except lag times for $\mathrm{BH}$ of cis-C18:2 and cis-C18:3 from $\mathrm{EBC}$ (Table 3). The rate of $\mathrm{BH}$ was twice as high for cis-C18:2 and cis-C18:3 than for cis-C18:1 with RBC, and was higher after extrusion for cis-C18:2 and cis-

Table 4. In vitro experiment: effects of extrusion and time of incubation on the profile of fatty acids with 18 carbons from canola.

\begin{tabular}{|c|c|c|c|c|c|c|c|c|c|c|c|c|c|c|c|}
\hline \multirow[b]{3}{*}{ Treatment } & \multicolumn{15}{|c|}{ Time of incubation, $\mathrm{h}$} \\
\hline & \multicolumn{3}{|c|}{2} & \multicolumn{3}{|c|}{4} & \multicolumn{3}{|c|}{8} & \multicolumn{3}{|c|}{16} & \multicolumn{3}{|c|}{24} \\
\hline & $\mathrm{RBC}^{1}$ & $\mathrm{EBC}^{2}$ & SEM & $\mathrm{RBC}$ & $\mathrm{EBC}$ & SEM & $\mathrm{RBC}$ & $\mathrm{EBC}$ & SEM & $\mathrm{RBC}$ & $\mathrm{EBC}$ & SEM & $\mathrm{RBC}$ & $\mathrm{EBC}$ & SEM \\
\hline & \multicolumn{15}{|c|}{ (\% of C18) } \\
\hline C18:0 & 16.48 & 11.13 & 3.19 & $33.18^{\mathrm{b}}$ & $38.12^{\mathrm{a}}$ & 1.24 & 51.87 & 53.06 & 1.99 & 70.36 & 67.1 & 1.84 & 76.87 & 72.98 & 1.59 \\
\hline$c i s-\mathrm{C} 18: 1^{3}$ & 49.08 & 52.63 & 2.22 & $37.29^{\mathrm{a}}$ & $33.65^{\mathrm{b}}$ & 1.10 & 23.77 & 21.71 & 1.20 & 11.33 & 11.24 & 0.74 & 8.63 & 9.56 & 1.04 \\
\hline trans-C18: $1^{3}$ & 5.89 & 4.15 & 0.54 & $8.20^{\mathrm{d}}$ & $12.36^{\mathrm{c}}$ & 0.59 & $11.76^{\mathrm{b}}$ & $15.18^{\mathrm{a}}$ & 0.73 & $11.16^{\mathrm{b}}$ & $13.65^{\mathrm{a}}$ & 0.74 & 10.78 & 11.83 & 0.75 \\
\hline cis-C18: $3^{3}$ & 6.66 & 7.62 & 0.51 & $4.56^{\mathrm{c}}$ & $2.76^{\mathrm{d}}$ & 0.25 & $2.27^{\mathrm{c}}$ & $1.00^{\mathrm{d}}$ & 0.26 & 0.55 & 0.64 & 0.13 & 0.09 & 0.51 & 0.17 \\
\hline
\end{tabular}

a,b,c,d Means in the same row and for the same incubation time with unlike superscripts differ (a, b, $P<0.05 ; \mathrm{c}, \mathrm{d}, P<0.01$ ).

${ }^{1} \mathrm{RBC}$ : raw blend of ground canola seeds and canola meal.

${ }^{2} \mathrm{EBC}$ : extruded blend of canola seeds and canola meal.

${ }^{3}$ cis-C18:1 refers to cis- $\Delta 9 \mathrm{C} 18: 1$, trans-C18:1 refers to trans- $\Delta 10 \mathrm{C} 18: 1+$ trans- $\Delta 11 \mathrm{C} 18: 1$, cis-C $18: 2$ refers to cis- $\Delta 9$, cis- $\Delta 12 \mathrm{C} 18: 2$, CLA refers to cis- $\Delta 9$, trans- $\Delta 11 \mathrm{C} 18: 2$, cis-C18:3 refers to $c i s-\Delta 9$, cis- $\Delta 12$, cis- $\Delta 15 \mathrm{C} 18: 3$. 

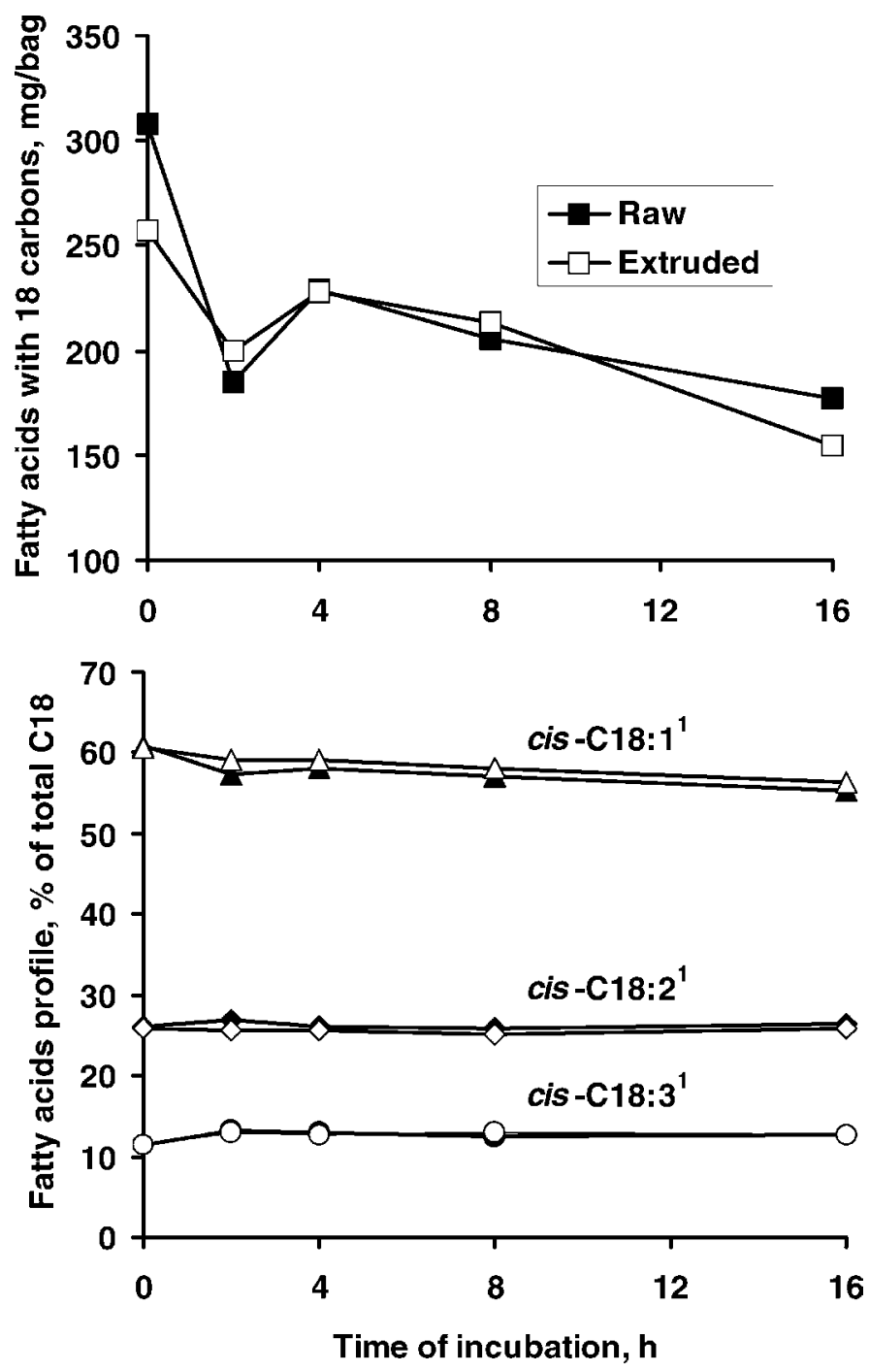

Figure 1. Effects of incubation of bags containing canola in sterilized rumen fluid with added pancreatin on disappearance of fatty acids with 18 carbons and evolution of their profile. ${ }^{1}$ cis-C18:1 refers to $c i s-\Delta 9 \mathrm{C} 18: 1$, cis-C18:2 refers to cis- $\Delta 9$, cis- $\Delta 12 \mathrm{C} 18: 2$, cis-C18:3 refers to cis- $\Delta 9$, cis- $\Delta 12$, cis- $\Delta 15 \mathrm{C} 18: 3$.

C18:3. The proportions of $c i s-\mathrm{C} 18: 1$, cis-C18:2, and cis$\mathrm{C} 18: 3$ at $4 \mathrm{~h}$ of incubation, and of cis-C18:2 and cis$\mathrm{C} 18: 3$ at $8 \mathrm{~h}$ of incubation, were lower with EBC (Table 4). By contrast, at $4 \mathrm{~h}$ of incubation, proportions of C18:0, trans-C18:1, and CLA were higher with EBC, and trans-C18:1 remained higher with EBC at 8 and $16 \mathrm{~h}$ of incubation. The proportion of trans-C18:1 decreased very slowly from $8 \mathrm{~h}$ of incubation, so that transC18:1 was the most abundant UFA at $24 \mathrm{~h}$ of incubation.

The disappearance and the profile of FA in bags incubated in sterilized ruminal fluid with added pancreatin are shown on Figure 1. The profiles of FA were similar

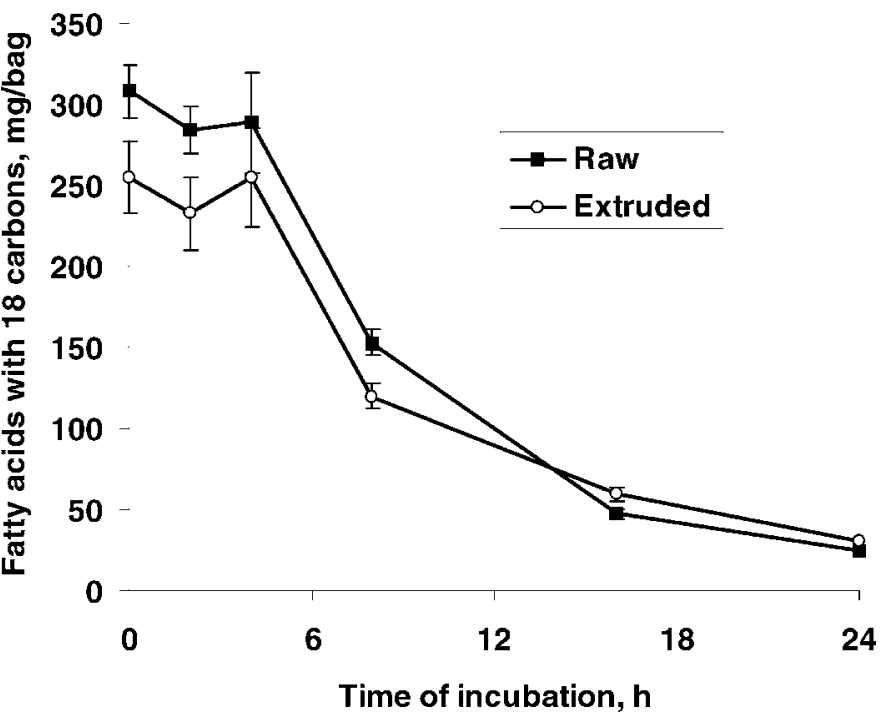

Figure 2. In situ experiment: disappearance of fatty acids with 18 carbons from canola. Error bars are \pm SE.

to the profile of $\mathrm{FA}$ in $\mathrm{RBC}$ or $\mathrm{EBC}$ for all incubation times, showing that the rate of loss through the bag was similar for all FA. In the in situ experiment, disappearance of total C18 through the bag was rapid after $4 \mathrm{~h}$ of incubation (Figure 2), so that only about $30 \mathrm{mg}$ of total $\mathrm{C} 18$ remained in the bag at $24 \mathrm{~h}$ of incubation. Lag times for $\mathrm{BH}$ of UFA were significantly greater than zero with EBC (Table 5). Lag times for BH of cisC18:2 and cis-C18:3 were significantly higher than in the in vitro experiment (Table 6) but were not affected by extrusion. Extrusion resulted in higher rates of $\mathrm{BH}$ of cis-C18:2 and cis-C18:3 (Table 5). Rates of $\mathrm{BH}$ of all UFA were on average four times as low as in the in vitro experiment. This difference was highly significant, and no interaction of method of investigation by extrusion was observed (Table 6). Extrusion resulted in lower proportions of cis-C18:2 and cis-C18:3 and higher proportions of C18:0, trans-C18:1 and CLA at $8 \mathrm{~h}$ of incubation (Table 7). Proportions of cis-C18:2 and cis-C18:3 remained numerically lower at $16 \mathrm{~h}$ of incubation and significantly lower at $24 \mathrm{~h}$ of incubation with EBC.

\section{DISCUSSION}

\section{Effect of the Method of Investigation on the Kinetics of Biohydrogenation of Fatty Acids from Canola}

A lag time has not been described in previous in vitro kinetics studies when cis-C18:2 (Harfoot et al., 1973a; Kellens et al., 1986; Beam et al., 2000) or soybean oil (Beam et al., 2000) were added as a lipid source. In situ lag times for $\mathrm{BH}$ of UFA were between 1 and $2 \mathrm{~h}$, so 
Table 5. In situ experiment: lag time and rate of biohydrogenation of unsaturated fatty acids from canola (mean $\pm \mathrm{SEM})$.

\begin{tabular}{|c|c|c|}
\hline Treatment & Raw & Extruded \\
\hline \multicolumn{3}{|l|}{ cis-C18: $1^{1}$} \\
\hline Lag time, $\mathrm{h}$ & $1.06 \pm 1.03$ & $1.69^{\mathrm{a}} \pm 0.67$ \\
\hline Rate of biohydrogenation, $\% / \mathrm{h}$ & $2.6 \pm 0.3$ & $3.4 \pm 0.2$ \\
\hline 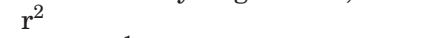 & 0.99 & 0.99 \\
\hline \multicolumn{3}{|l|}{ cis-C18:2 ${ }^{1}$} \\
\hline Lag time, $\mathrm{h}$ & $1.90 \pm 1.05$ & $1.84^{\mathrm{a}} \pm 0.33$ \\
\hline Rate of biohydrogenation, $\% / \mathrm{h}$ & $4.8^{c} \pm 0.7$ & $10.0^{\mathrm{b}} \pm 0.8$ \\
\hline $\mathrm{r}^{2}$ & 0.99 & 0.99 \\
\hline \multicolumn{3}{|l|}{ cis-C18: $3^{1}$} \\
\hline Lag time, $\mathrm{h}$ & $1.85 \pm 1.10$ & $1.69^{a} \pm 0.33$ \\
\hline Rate of biohydrogenation, $\% / \mathrm{h}$ & $4.9^{\mathrm{c}} \pm 0.8$ & $12.5^{\mathrm{b}} \pm 1.2$ \\
\hline $\mathrm{r}^{2}$ & 0.97 & 0.98 \\
\hline
\end{tabular}

${ }^{a}$ Value significantly different from zero $(P<0.05)$.

${ }^{\mathrm{b}, \mathrm{c}}$ Means in the same row with unlike superscripts differ $(P<0.01) .{ }^{1}$ cis-C18:1 refers to cis- $\Delta 9 \mathrm{C} 18: 1$, cisC18:2 refers to $c i s-\Delta 9, c i s-\Delta 12 \mathrm{C} 18: 2$, cis-C18:3 refers to $c i s-\Delta 9, c i s-\Delta 12, c i s-\Delta 15 \mathrm{C} 18: 3$.

the FA profile at $2 \mathrm{~h}$ of incubation was similar to that of canola blends. Perrier et al. (1992), measuring total in situ disappearance of individual FA due both to loss of particles and to $\mathrm{BH}$ reported, at $4 \mathrm{~h}$ of incubation, disappearances around 40 and $42 \%$ for total FA and cis-C18:2, respectively, which suggests that $\mathrm{BH}$ of cisC18:2 was very limited during the first $4 \mathrm{~h}$ incubation and was consistent with an important lag time. This could be due to a lag time for lipolysis, because ruminal $\mathrm{BH}$ can only occur on FFA, not on FA in triacylglycerols (Hawke and Silcock, 1969). Previous studies have shown that lipolysis of triacylglycerols is very rapid in the rumen (Garton et al., 1958; Beam et al., 2000), and such an hypothesis would not explain the difference between the in situ and the in vitro experiments. Such a lag time has often been reported for the degradation of fiber, due to time for colonization of the bags and adhesion of cellulolytic bacteria on cell walls. The BH is known to occur on FA adsorbed onto feed particles (Harfoot et al., 1973b). One of the most important bacteria for $\mathrm{BH}$ is a cellulolytic bacterium, Butyrivibrio fibri-

Table 6. Significance of effects of method of investigation and interaction of method of investigation by extrusion on lag time and rate of biohydrogenation of unsaturated fatty acids from canola.

\begin{tabular}{lll}
\hline & $\begin{array}{l}\text { Method of } \\
\text { investigation }\end{array}$ & $\begin{array}{l}\text { Interaction } \\
\text { method } \times \text { extrusion }\end{array}$ \\
\hline $\begin{array}{l}\text { cis-C18: } 1^{1} \\
\text { Lag time }\end{array}$ & NS & NS \\
$\begin{array}{l}\text { Rate of biohydrogenation } \\
\text { cis-C18:2 }\end{array}$ & $P<0.01$ & NS \\
Lag time & $P<0.05$ & NS \\
Rate of biohydrogenation & $P<0.01$ & NS \\
cis-C18:3 & & \\
Lag time & $P<0.05$ & NS \\
Rate of biohydrogenation & $P<0.01$ & NS \\
\hline
\end{tabular}

${ }^{1}$ cis-C18:1 refers to cis- $\Delta 9 \mathrm{C} 18: 1$, cis-C18:2 refers to cis- $\Delta 9$, cis$\Delta 12 \mathrm{C} 18: 2$, cis-C18:3 refers to cis- $\Delta 9$, cis- $\Delta 12$, cis- $\Delta 15 \mathrm{C} 18: 3$. solvens (Polan et al., 1964), so that the BH of FA could require a similar lag time than degradation of fiber in situ. By contrast, in this in vitro experiment hay was incubated in the rumen and provided cellulolytic bacteria already attached onto particles. Therefore, stirring the flask could result in a rapid adsorption of lipids onto hay particles, resulting in lower lag times for $\mathrm{BH}$.

Comparing in vitro batch cultures and in situ methods for the study of NDF degradation, Varel and Kreikemeier (1995) obtained lower lag times in situ than in vitro. The opposite results on UFA in this experiment could be due 1) to intrinsic differences between lag times for fibrolysis and $\mathrm{BH}$ by bacteria or 2) to differences of colonization pattern between main cellulolytic bacteria and bacteria that are both cellulolytic and responsible for $\mathrm{BH}$, or 3 ) to a slow penetration of bacteria into the nylon bag because of hydrophobicity of canola, contrasting with a rapid dispersion of the lipids in the in vitro experiment.

The $\mathrm{BH}$ of UFA was rapid in this in vitro experiment. Previous in vitro studies have often focused on the $\mathrm{BH}$ of cis-C18:2 and resulted in contrasting results. Reddy et al. (1994) found that BH of cis-C18:2 from raw soybeans was $79.8 \%$ at $24 \mathrm{~h}$ of incubation when calculated with the proportion of cis-C18:2 in total C18, which means that the ratio $c i s-\mathrm{C} 18: 2 /$ total $\mathrm{C} 18$ was five times as low at $24 \mathrm{~h}$ than initially. In this experiment, this ratio was 30 times as low than initially at $24 \mathrm{~h}$. Beam et al. (2000) also published slower rates of $\mathrm{BH}$ of cis$\mathrm{C} 18: 2$, ranging from 8 to $12 \% / \mathrm{h}$. By contrast, $\mathrm{Wu}$ and Palmquist (1991) found that the in vitro $\mathrm{BH}$ of cis-C18:2 from an animal-vegetable fat blend was about $90 \%$ at only $4 \mathrm{~h}$ of incubation, which implies a rate of $\mathrm{BH}$ around 40\%. Van Nevel and Demeyer (1996) published $\mathrm{BH}$ over $90 \%$ for cis-C18:2 from soybean oil at $6 \mathrm{~h}$ of incubation. Similarly, conflicting results have been pub- 
lished about $\mathrm{BH}$ of cis-C18:1, with an extent of $\mathrm{BH}$ between 50 and $60 \%$ at $4 \mathrm{~h}$ of incubation (Wu and Palmquist, 1991), or a rate of approximately $3.6 \% / \mathrm{h}$ (Beam et al., 2000). Such large variations among experiments, including ours, can be related to experimental conditions, because in vitro $\mathrm{BH}$ depends on the starch content of the substrate (Gerson et al., 1985), the $\mathrm{N}$ content (Gerson et al., 1983), the $\mathrm{pH}$ (Van Nevel and Demeyer, 1996), and the size of particles (Gerson et al., 1988). Ruminal $\mathrm{BH}$ of cis-C18:3 in vitro has been reported to be in the same range as $\mathrm{BH}$ of cis-C18:2 (Wu and Palmquist, 1991), which is consistent with results of the current experiment.

Depending on the source and amount of added unprotected fat, $\mathrm{BH}$ has been reported to be in the range 60 to $73 \%, 75$ to $87 \%$, and 83 to $88 \%$ in vivo for cis-C18:1, cis-C18:2, and cis-C18:3 (Murphy et al., 1987; Wu et al, 1991). In vitro calculations from $B H$ kinetic parameters reported in Table 3 indicate that these ranges of $\mathrm{BH}$ were attained between 8 and $12 \mathrm{~h}$ of incubation with RBC. By contrast, such BH was not yet attained at 24 $\mathrm{h}$ of incubation in situ, because of much lower rates of $\mathrm{BH}$.

Perrier et al. (1992) reported, in an in situ experiment with ground soybeans as a substrate, that at $8 \mathrm{~h}$ of incubation disappearances were about 60 and $75 \%$ for total FA and cis-C18:2, respectively. From these results, it can be calculated that the percentage of $\mathrm{cis}$-C18:2 in total FA, which was initially $50 \%$, decreased to about $30 \%$ at $8 \mathrm{~h}$ of incubation, which suggests a slow $\mathrm{BH}$. In this experiment, using $\mathrm{BH}$ kinetic parameters reported in Table 5 , it can be calculated that a similar $40 \%$ decrease of the proportion of cis-C18:2 with RBC was reached at $13 \mathrm{~h}$ of incubation. A slow penetration of bacteria into the bag, or the lack of fibrous particles in the bag, could also explain the lower rate of $\mathrm{BH}$ observed in situ than in vitro, contrasting with higher degradation rates of fiber observed by Varel and Kreikemeier (1995), but consistent with lower degradation rates of proteins observed by Broderick et al. (1988). Under this hypothesis, mixing a source of fiber with the source of fat in the bags could hasten both adsorption of lipids and adhesion of bacteria onto particles, resulting in lower lag times and higher rates of $\mathrm{BH}$.

An important accumulation of trans-C18:1 was observed, especially in situ. At $24 \mathrm{~h}$ of incubation, transC18:1 represented $23.9 \%$ of total $\mathrm{C} 18$ remaining in the bags with $\mathrm{RBC}$, and from the beginning of incubation, the percentages of cis-C18:2 plus cis-C18:3, which both are precursors of trans-C18:1 (Harfoot and Hazlewood, 1988), had decreased from 37.5 to $15.0 \%$, which means that nearly all the cis-C18:2 and cis-C18:3 that disappeared were transformed into trans-C18:1, not C18:0. Consistently, at $24 \mathrm{~h}$ of incubation, the increase of C18:0 
and the decrease of $c i s-\mathrm{C} 18: 1$ proportions were similar. Accumulation of trans-C18:1 as the major end-product of $\mathrm{BH}$ of cis-C18:2 has been described in vitro (Wu and Palmquist, 1991), and when the initial concentration of cis-C18:2 is over $1 \mathrm{mg} / \mathrm{ml}$, the inhibition of $\mathrm{BH}$ of trans-C18:1 to C18:0 is irreversible (Harfoot et al., 1973a). In this in vitro experiment, the initial concentration of cis-C18:2, including cis-C18:2 from substrate and inoculum, was about $0.28 \mathrm{mg} / \mathrm{ml}$, so that transC18:1 did not accumulate as a major end-product. In the in situ experiment, the initial concentration of cis$\mathrm{C} 18: 2$ in the bags was $36 \mathrm{mg} / \mathrm{g}$, which probably resulted in concentrations of $c i s-\mathrm{C} 18: 2$ largely over $1 \mathrm{mg} / \mathrm{ml}$ after penetration of ruminal fluid into the bags.

\section{Effect of the Method of Investigation on the Modifications of Biohydrogenation Due to Extrusion}

Both in vitro and in situ, the rates of $\mathrm{BH}$ of cis-C18:2 and $c i s-\mathrm{C} 18: 3$ were much higher with EBC. This could be due to the rupture of cell membranes, with an increased availability of free oil for ruminal fermentation (Reddy et al., 1994). In their experiment, Reddy et al. (1994) found in vitro that extrusion of soybeans lowered the extent of $\mathrm{BH}$, but with an initial concentration of cis-C18:2 that was much higher than in this experiment, which could have affected lipolysis and $\mathrm{BH}$ (Beam et al., 2000).

This faster $\mathrm{BH}$ with $\mathrm{EBC}$ resulted in lower proportions of UFA at 4 and $8 \mathrm{~h}$ of incubation in vitro and 8 $\mathrm{h}$ of incubation in situ. However, this faster disappearance seemed to be related mainly to the first step of ruminal $\mathrm{BH}$ (i.e., isomerization) because extrusion also resulted in higher concentrations of CLA and transC18:1. The ratios of CLA to disappeared cis-C18:2 and of trans-C18:1 to disappeared (cis-C18:2 + cis-C18:3) were similar with $\mathrm{RBC}$ and $\mathrm{EBC}$, suggesting that rates of $\mathrm{BH}$ of these intermediates were not affected by extrusion. Lack of effect of extrusion on the rate of $\mathrm{BH}$ of cis-C18:1 is consistent with an effect of extrusion on the isomerization of polyunsaturated FA because $\mathrm{BH}$ of $c i s-\mathrm{C} 18: 1$ does not require the action of an isomerase.

Comparing raw and extruded soybeans in situ, Chouinard et al. (1997b) found that the concentrations of all C18 FA in the bags were higher with extruded soybeans and outlined that these results were consistent with higher trans-C18:1 proportions in plasma and milk, but contrasted with lower cis-C18:2 and cis-C18:3 proportions in milk. In this experiment, extrusion resulted, both in vitro and in situ, in higher proportions of trans-C18:1 and CLA and lower proportions of cis$\mathrm{C} 18: 2$ and cis-C18:3, which is consistent with the variations of milk fat composition observed when extruded soybeans are compared to raw ground soybeans
(Chouinard et al., 1997a, 1997b). The differences between these in situ results and the results published by Chouinard et al. (1997b) are due to differences in the method of expression of FA disappearance, because calculations of these authors did not separate disappearance due to loss of particles and disappearance due to $\mathrm{BH}$.

Compared to a control diet without added fat, the increase of proportion of trans-C18:1 in milk is much higher with added extruded canola than with added raw ground canola (Bayourthe et al., 2000), which is consistent with the increased peak proportions of transC18:1 observed in these experiments. Similarly, with EBC, the peak proportion of CLA was 4 and 3 times as high as with RBC in vitro and in situ, respectively. Such ratios are consistent with the threefold greater concentration of CLA in milk from cows receiving extruded soybeans compared with cows receiving raw ground soybeans (Chouinard et al., 2001), which could also have resulted from a mammary desaturation of trans-C18:1 (Griinari et al., 2000).

\section{CONCLUSIONS}

Extrusion of canola increased the rate of $\mathrm{BH}$ of UFA and the proportions of intermediates of $\mathrm{BH}$ that fit with the concern of increasing the concentration of CLA in milk and milk products. In vitro and in situ studies resulted in different estimates of the rates of $\mathrm{BH}$ of UFA, but resulted in similar differences between RBC and EBC. In conclusion, both methods can be used to study differences of rates of $\mathrm{BH}$ due to treatment of oilseeds. More research is needed to ascertain whether a slow microbial colonization or a high initial concentration of cis-C18:2 in the in situ method can explain the low $\mathrm{BH}$ rates observed with this method.

\section{REFERENCES}

Adlof, R. O., S. Duval, and E. A. Emken. 2000. Biosynthesis of conjugated linoleic acid in humans. Lipids 35:131-135.

Bayourthe, C., F. Enjalbert, and R. Moncoulon. 2000. Effects of different forms of canola oil fatty acids plus canola meal on milk composition and physical properties of butter. J. Dairy Sci. 83:690-696.

Beam, T. M., T. C. Jenkins, P. J. Moate, R.A. Kohn, and D. L. Palmquist. 2000. Effects of amount and source of fat on the rates of lipolysis and biohydrogenation of fatty acids in ruminal contents. J. Dairy Sci. 83:2564-2573.

Broderick, G. A., R. J. Wallace, E. R. Ørskov, and L. Hansen. 1988. Comparison of estimates of ruminal protein degradation by in vitro and in situ methods. J. Anim. Sci. 66:1739-1745.

Chouinard, P. Y., L. Corneau, W. R. Butler, Y. Chilliard, J. K. Drackley, and D. E. Bauman. 2001. Effect of dietary lipid source on conjugated linoleic acid concentrations in milk fat. J. Dairy Sci. 84:680-690.

Chouinard, P. Y., V. Girard, and G. J. Brisson. 1997a. Performance and profiles of milk fatty acids of cows fed full fat, heat-treated soybeans using various processing methods. J. Dairy Sci. 80:334-342. 
Chouinard, P. Y., J. Lévesque, V. Girard, and G. J. Brisson. 1997b. Dietary soybeans extruded at different temperatures: milk composition and in situ fatty acid reactions. J. Dairy Sci. 80:29132924.

Enjalbert, F., M. C. Nicot, C. Bayourthe, M. Vernay, and R. Moncoulon. 1997. Effects of dietary calcium soaps of unsaturated fatty acids on digestion, milk composition, and physical properties of butter. J. Dairy Res. 64:181-195.

Garton, G. A., P. N. Hobson, and A. K. Lough. 1958. Lipolysis in the rumen. Nature 182:1511-1512.

Gerson, T., A. John, and A. S. D. King. 1985. The effects of dietary starch and fiber on the in vitro rates of lipolysis and hydrogenation by sheep rumen digesta. J. Agric. Sci. (Camb.) 105:27-30.

Gerson, T., A. John, and B. R. Sinclair. 1983. The effects of dietary $\mathrm{N}$ on in vitro rates of lipolysis and fatty acids hydrogenation in rumen digesta from sheep fed diets high in starch. J. Agric. Sci. (Camb.) 101:97-101.

Gerson, T., A.S.D. King, K. E. Kelly, and W. J. Kelly. 1988. Influences of particle size and surface area on in vitro rates of gas production, lipolysis of triacylglycerol. and hydrogenation of linoleic acid by sheep rumen digesta or Ruminococcus flavefaciens. J. Agric. Sci. (Camb.) 110:31-37.

Griinari, J. M., B. A. Corl, S. H. Lacy, P. Y. Chouinard, K. V. Nurmela, and D. E. Bauman. 2000. Conjugated linoleic acid is synthesized endogenously in lactating dairy cows by $\Delta 9$-desaturase. J. Nutr. 130:2285-2291.

Harfoot, C. G., and G. P. Hazlewood. 1988. Lipid metabolism in the rumen. Pages 285-322 in The Rumen Microbial Ecosystem. P. N. Hobson, ed. Elsevier, Barking, United Kingdom.

Harfoot, C. G., R. C. Noble, and J. H. Moore. 1973a. Factors influencing the extent of biohydrogenation of linoleic acid by rumen microorganisms in vitro. J. Sci. Food. Agric. 24:961-970.

Harfoot, C. G., R. C. Noble, and J. H. Moore. 1973b. Food particles as a site for biohydrogenation of unsaturated fatty acids in the rumen. Biochem. J. 132:829-832.
Hawke, J. C., and W. R. Silcock. 1969. Lipolysis and hydrogenation in the rumen. Biochem. J. 112:131-132.

Kellens, M. J., H. L. Goderis, and P. P. Tobback. 1986. Biohydrogenation of unsaturated fatty acids by a mixed culture of rumen microorganisms. Biotechnol. Bioeng. 28:1268-1276.

Murphy, M., P. Udén, D. L. Palmquist, and H. Wiktorson. 1987. Rumen and total diet digestibilities in lactating cows fed diets containing full-fat rapeseed. J. Dairy Sci. 70:1572-1582.

OØrskov, E. R., and J. McDonald. 1979. The estimation of protein degradability in the rumen from incubation measurements weighed according to rate of passage. J. Agric. Sci. (Camb.) 92:499-503.

Perrier, R., B. Michalet-Doreau, D. Bauchart, and M. Doreau. 1992. Assessment of an in-situ technique to estimate the degradation of lipids in the rumen. J. Sci. Food Agric. 59:449-455.

Polan, C. E., J. J. McNeill, and C. B. Tove. 1964. Biohydrogenation of unsaturated fatty acids by rumen bacteria. J. Bacteriol. 88:1056-1064.

Reddy, P. V., J. L. Morrill, and T. G. Nagaraja. 1994. Release of free fatty acids from raw or processed soybeans and subsequent effects on fiber digestibilities. J. Dairy Sci. 77:3410-3416.

Sukhija, P.S., and D. L. Palmquist. 1988. Rapid method for determination of total fatty acid content and composition of feedstuffs and feces. J. Agric. Food Chem. 36:1202-1206.

Van Nevel, C. J., and D. I. Demeyer. 1996. Influence of pH on lipolysis and biohydrogenation of soybean oil by rumen contents in vitro. Rep. Nutr. Dev. 36:53-63.

Varel, V. H., and K. K. Kreikemeier. 1995. Technical note: comparison of in vitro and in situ digestibility methods. J. Anim. Sci. 73:578-582.

Wu, Z., A. Ohajuruka, and D. L. Palmquist. 1991. Ruminal synthesis, biohydrogenation, and digestibility of fatty acids by dairy cows. J. Dairy Sci. 74:3025-3034.

Wu, Z., and D. L. Palmquist. 1991. Synthesis and biohydrogenation of fatty acids by ruminal microorganisms in vitro. J. Dairy Sci. 74:3035-3046. 